\title{
Hubungan antara Faktor Klinikohistopatologi dan Kualitas Hidup Pasien Kanker Endometrium Pasca Operasi di RSUP Dr. Sardjito Yogyakarta Menggunakan Modul Kuesioner EORTC QLQ-C30 dan EN 24
}

\author{
Dini Mahrani ${ }^{1}$, Ahsanudin Attamimi², Ardhanu Kusumanto ${ }^{3}$ \\ 1,2,3 Departemen Obstetri dan Ginekologi, Fakultas Kedokteran, Kesehatan Masyarakat dan Keperawatan, \\ Universitas Gadjah Mada, RSUP Dr Sardjito, Yogyakarta, Indonesia \\ Korespondensi: dinimahrani263@gmail.com
}

Submisi: 26 Februari 2021; Revisi:20 Maret 2021; Penerimaan: 29 Maret 2021

\begin{abstract}
Background: According to data from the "Endometrial Cancer Report" by the World Cancer Research Fund and the American Institute for Cancer Research (WCRFI), endometrial cancer is the sixth most common malignancy in the world and is the largest cancer in female organs, after cervical cancer. ${ }^{1,2,3,4}$ This incidence is increasing every year, it is predicted to increase about $5 \%$ of new cases each year. The main prognostic factors of endometrial cancer are determined by the histological type, stage, degree, differentiation of the tumor, invasive myometrial level and increase in lympho-vascular invasion. In addition to determining the histopathological factors, the prognosis is also determined from the clinical patient. $25,5,6,7$ Several studies have shown certain clinical factors also improve the condition and prognosis of the disease. ${ }^{7,8,9,10}$ Prognosis of this disease with the quality of life of patients becomes an interesting topic to discuss. Besides that quality of life is also a measure of therapeutic success. The better the prognosis of a disease, the better the quality of life, the higher the success rate of therapy. ${ }^{11,12}$

Objective: To know correlation between clinicohistopathological and quality of life in patients with endometrial cancer after undergoing surgery at Sardjito Hospital, Yogyakarta.

Method: The research is analytic with cross sectional approach. Patients with endometrial cancer who have undergone total hysterectomy and bisalpingoophorectomy surgery are assessed for their quality of life through interviews and filling out questionnaires in the EORTC QLQ-C 30 and QLQ-EN 24 modules.

Results and Discussion: TThis study, most people with endometrial cancer aged 55-65 years were 34 people (42\%) and diagnosed after menopause with a range of age $>55$ years as many as 43 people (53.1\%). This study cannot prove the hypothesis that age, parity, body mass index, type of histopathology and KGB involvement have a relationship with the quality of life of cancer patients ( $p>0.05)$. But in contrast to the stage of early cancer (OR 3.17, $\mathrm{p}=0.044$ ( $\mathrm{Cl} 95 \%$ 1.03-9.75)) and good and moderate differentiation (OR 4.471, $\mathrm{p}=0.023$ (Cl 95\% 1.23-16.24)) have a significant relationship with quality of life.
\end{abstract}

Conclusion: Clinicohistopathological factors (cancer stage and tumor differentiation) have a correlation with the quality of life at patients with postoperative endometrial cancer in Sardjito Hospital.

Keywords: Endometrial cancer; clinicohistopathological factors; quality of life

\begin{abstract}
ABSTRAK
Latar Belakang: Menurut data "Endometrial Cancer 2013 report" oleh World Cancer Research Fund and American Institute for Cancer Research (WCRFI), kanker endometrium merupakan keganasan wanita keenam yang terbanyak diseluruh dunia dan merupakan kanker kedua terbesar pada organ reproduksi wanita, setelah kanker serviks. ${ }^{1,2,3,4}$ Insidensi ini meningkat setiap tahunnya, diprediksikan peningkatan sekitar $5 \%$ kasus baru setiap tahunnya. Faktor prognosis utama kanker endometrium ditentukan oleh jenis histologis, stadium, grade, differensiasi tumor, kedalaman invasi miometrium dan keterlibatan dari invasi limfo-vaskular. Selain dipengaruhi faktor histopatologi tersebut, prognosis juga ditentukan dari klinis penderita. ${ }^{2,5,6,7}$ Beberapa penelitian terdahulu membuktikan beberapa faktor klinis tertentu juga mempengaruhi kondisi dan prognosis penyakit. $7,8,9,10$ Adanya kemungkinan kaitan prognosis penyakit ini dengan kualitas hidup penderita menjadi topik yang menarik untuk dibahas. Disamping itu kualitas hidup juga merupakan alat ukur keberhasilan terapi. Semakin baik prognosis suatu penyakit maka kualitas hidup juga akan semakin baik, maka angka keberhasilan terapi juga semakin tinggi. ${ }^{11,12}$
\end{abstract}

Tujuan: Mengetahui hubungan klinikohistopatologi terhadap kualitas hidup pasien kanker endometrium setelah menjalani operasi di RSUP Sardjito, Yogyakarta. 
Metode: Penelitian bersifat analitik dengan pendekatan cross sectional. Penderita kanker endometrium yang telah menjalani operasi histerektomi total dan bisalpingooforektomi dinilai kualitas hidupnya melalui wawancara dan pengisisan kuesioner modul EORTC QLQ-C 30 dan QLQ-EN 24.

Hasil dan Pembahasan: Penelitian ini sebagian besar penderita kanker endometrium berusia 55-65 tahun sebanyak 34 orang (42\%) dan terdiagnosis setelah menopause dengan kisaran usia $>55$ tahun sebanyak 43 orang $(53,1 \%)$. Pada penelitian ini tidak dapat membuktikan hipotesis bahwa usia, paritas, indeks massa tubuh, jenis histopatologi dan keterlibatan KGB memiliki hubungan dengan kualitas hidup penderita kanker ( $p>0,05$ ). Namun berbeda dengan stadium kanker dini (OR 3,17, p=0,044 (CI 95\% 1,03-9,75)) dan differensiasi baik dan sedang (OR 4,471, p=0,023 (CI 95\% 1,23-16,24)) memiliki hubungan yang signifikan dengan kualitas hidup.

Kesimpulan: Faktor klinikohistopatologi berupa stadium kanker dan differensiasi tumor memiliki hubungan dengan kualitas hidup pasien kanker endometrium pasca operasi di RSUP Dr. Sardjito.

Kata Kunci: Kanker endometrium; faktor klinikohistopatologi; kualitas hidup

\section{PENDAHULUAN}

Kanker endometrium merupakan penyakit ganas dengan angka kejadian dan angka mortalitas yang tinggi di dunia. Menurut data "Endometrial Cancer 2013 report" oleh World Cancer Research Fund and American Institute for Cancer Research (WCRFI, kanker endometrium adalah keganasan wanita keenam terbanyak diseluruh dunia dan kanker kedua terbesar pada organ reproduksi wanita, setelah kanker serviks. ${ }^{13,14}$ Insidensi ini meningkat setiap tahunnya, diprediksikan peningkatan sekitar lima persen kasus baru setiap tahunnya.. Kanker endometrium didefinisikan sebagai tumor epitel ganas primer, biasanya dengan diferensiasi kelenjar, yang berpotensi menginvasi ke dalam miometrium dan menyebar ke lokasi yang jauh., ${ }^{2,15}$ Ada beberapa faktor prognosis yang sangat berperan dalam menilai angka kekambuhan penyakit. Faktor prognosis utama kanker endometrium ditentukan oleh jenis histologis, stadium, grade, differensiasi tumor, kedalaman invasi miometrium dan keterlibatan dari invasi limfo-vaskular. Selain dipengaruhi faktor histopatologi tersebut, prognosis juga ditentukan dari klinis penderita. ${ }^{8,16,17,18}$ Salah satu alat ukur untuk melihat keberhasilan terapi terutama pada kanker ataupun penyakit kronis lainnya yang memiliki kemungkinan kesembuhan yang sangat kecil adalah dengan menggunakan skala kualitas hidup. Kualitas hidup merupakan gambaran kesejahteraan atau kenyamanan pasien baik sebelum dan sesudah pengobatan. ${ }^{19,20,21,22}$ Tingkat keparahan, keefektifan pengobatan dan besarnya dampak penyakit terhadap pasien dapat digambarkan dengan menilai kualitas. Semakin baik prognosis suatu penyakit maka kualitas hidup juga akan semakin baik, maka angka keberhasilan terapi juga semakin tinggi. ${ }^{11,12}$

\section{METODE}

Rancangan penelitian ini adalah analitik dengan pendekatan cross sectional (Siswosudarmo, 2015). Pasien didiagnosis dengan kanker endometrium yang telah menjalani operasi histerektomi total dan bisalpingooforektomi dimulai pada januari 2017 hingga desember 2018 (kurun waktu dua tahun terakhir), kemudian dinilai kualitas hidupnya. Penilaian kualitas hidup pasien dilakukan dengan wawancara dan mengisi kuosioner berdasarkan modul EORTC QLQ-C 30 dan QLQ-EN 24. ${ }^{23,24,25}$ Subjek penelitian adalah faktor-faktor klinikohistopatologi sebagai faktor prognosis dari kanker endometrium yang dapat mempengaruhi kualitas hidup penderitanya. Penelitian dilakukan di RSUP dr. Sardjito Yogyakarta selama enam bulan yang dimulai sejak ethical approval diterbitkan. RSUP dr. Sardjito dipilih oleh karena sebagai pusat rujukan pasien-pasien dengan keganasan, sehingga lebih mudah dalam melakukan penelitian. Adapun syarat populasi memenuhi kriteria inklusi, antara lain: pasien kanker endometrium di RSUP $d r$. Sardjito Yogyakarta; pasien yang telah menjalani histerektomi total dan bisalpingooforektomi antara Januari 2017-Desember 2018; pasien sadar penuh dan dapat berkomunikasi dalam bahasa Indonesia; dan bersedia mengikuti penelitian. Dan kriteria eksklusinya antara lain jika: terdapat keganasan lain; pasien memiliki kondisi atau komplikasi medis yang lain; pasien dengan gangguan jiwa; pasien meninggal dunia; dan rekam medis tidak dapat ditemukan.

\section{HASIL DAN PEMBAHASAN}

Penelitian ini melibatkan 81 subyek penelitian yang memenuhi kriteria inklusi dan eksklusi. Kemudian dilakukan wawancara langsung terhadap subyek 
penelitian yang berlangsung di poliklinik Onkologi RSUP Dr. Sardjito Yogyakarta. Karakteristik pasien meliputi usia, status menopause, indeks massa tubuh (IMT), jumlah paritas, histopatologi, stadium kanker, differensiasi, limfadenektomi, keterlibatan KGB, kemoterapi dan radioterapi disajikan pada Tabel 1.

Tabel 1. Karakteristik Pasien Kanker Endometrium yang Telah Dilakukan Histerektomi Total dan Bisalpingooforektomi di Rsup Dr. Sardjito

\begin{tabular}{|c|c|c|}
\hline Karakteristik Penelitian & Jumlah & $\begin{array}{c}\text { Persentase } \\
\text { (\%) }\end{array}$ \\
\hline \multicolumn{3}{|l|}{ Usia } \\
\hline 26-35 tahun & 3 & $3,70 \%$ \\
\hline $36-45$ tahun & 12 & $14,80 \%$ \\
\hline 46-55 tahun & 23 & $28,40 \%$ \\
\hline $56-65$ tahun & 34 & $42,00 \%$ \\
\hline$>65$ tahun & 9 & $11,10 \%$ \\
\hline \multicolumn{3}{|l|}{ Status menopause } \\
\hline Sudah & 48 & $59,20 \%$ \\
\hline Belum & 33 & $40,80 \%$ \\
\hline \multicolumn{3}{|l|}{ Indeks massa tubuh (IMT) } \\
\hline Obesitas & 17 & $21,00 \%$ \\
\hline Non obesitas & 64 & $79,00 \%$ \\
\hline \multicolumn{3}{|l|}{ Jumlah paritas } \\
\hline 0 & 23 & $28,40 \%$ \\
\hline $1-2$ & 26 & $32,10 \%$ \\
\hline $3-4$ & 31 & $38,30 \%$ \\
\hline$>=5$ & 1 & $1,20 \%$ \\
\hline \multicolumn{3}{|l|}{ Jenis histopatologi } \\
\hline Endometrioid & 77 & $95,10 \%$ \\
\hline Non endometrioid & 4 & $4,90 \%$ \\
\hline \multicolumn{3}{|l|}{ Stadium } \\
\hline I & 35 & $43,20 \%$ \\
\hline IA & 11 & \\
\hline IB & 24 & \\
\hline II & 32 & $39,50 \%$ \\
\hline III & 13 & $16,10 \%$ \\
\hline IIIA & 1 & \\
\hline IIIB & 1 & \\
\hline IIIC & 11 & \\
\hline IV & 1 & $1,20 \%$ \\
\hline \multicolumn{3}{|l|}{ Differensiasi tumor } \\
\hline Baik+sedang & 53 & $65,40 \%$ \\
\hline Buruk & 28 & $34,60 \%$ \\
\hline
\end{tabular}

Persentase (\%)

\begin{tabular}{lll}
$\begin{array}{l}\text { Limfadenektomi } \\
\text { Tidak }\end{array}$ & 41 & $50,60 \%$ \\
Iya & 40 & $49,40 \%$ \\
Keterlibatan KGB & & \\
Tidak & 70 & $86,40 \%$ \\
Iya & 11 & $13,60 \%$ \\
Kemoterapi & & \\
Tidak & 30 & $37,00 \%$ \\
Iya & 51 & $63,00 \%$ \\
Radioterapi & & \\
Tidak & & $35,80 \%$ \\
Iya & 29 & $64,20 \%$ \\
\hline
\end{tabular}

Rata-rata usia penderita kanker endometrium yang masuk subjek penelitian ini berkisar antara 56-65 tahun yaitu 34 orang (42\%). Untuk penderita $<55$ tahun didapatkan sebanyak 38 orang dimana usia 26-35 tahun sebanyak 3 orang (3,7\%), 36-45 tahun sebanyak 12 orang (14,8\%) dan 46-55 tahun sebanyak 23 orang (28,4 \%). Untuk penderita kanker endometrium yang berusia lanjut $>65$ tahun ditemukan sebanyak 9 orang (11,1\%). Diantara subjek penelitian dengan usia <55 tahun didapatkan 33 orang $(40,8 \%)$ berstatus belum menopause saat sebelum dilakukannya tindakan pembedahan.

Berdasarkan paritasnya, rata-rata subjek memiliki kisaran jumlah paritas sebanyak 3-4 anak yaitu 31 orang (38,3\%). Sedangkan subjek yang memiliki status paritas nulipara (tidak memiliki anak) terdapat sebanyak 23 orang $(28,4 \%)$ dan grande multipara (memiliki $>5$ anak) sebanyak 1 orang $(1,2 \%)$. Selain itu, jika menilai status indeks massa tubuh (IMT) subjek penelitian, sebagian besar penderita kanker endometrium di RSUP Dr. Sardjito adalah wanita non obesitas dengan jumlah 64 orang (79\%), sedangkan penderita dengan obesitas sebanyak 17 orang (21\%). ${ }^{26}$

Jika menilai gambaran karakteristik histopatologi penderita kanker endometrium pada subjek penelitian ini, didapatkan 77 orang $(95,1 \%)$ dengan jenis histopatologi endometrioid dan hanya 4 orang $(4,9 \%)$ dengan jenis non endometrioid. Subjek pada umumnya memiliki stadium dini sebanyak 67 orang $(82,7 \%)$ dan stadium lanjut sebanyak 14 orang 
$(17,3 \%)$, dengan penggolongan stadiumnya antara lain: stadium I terdapat 35 orang $(43,2 \%)$ dengan stadium IA 11 orang dan stadium IB 24 orang, stadium II sebanyak 32 orang $(39,5 \%)$, stadium III sebanyak 13 orang (16\%) dengan stadium IIIA 1 orang, stadium IIIB 1 orang, dan stadium IIIC 11 orang; dan stadium IVA 1 orang (1,2\%).

Berdasarkan differensiasi tumor terdapat 53 orang $(65,4 \%)$ dengan kanker differensiasi baik, dimana diantaranya 42 orang $(79,2 \%)$ memiliki grade 1 (baik) dan 11 orang (20,8\%) grade 2 (sedang). Sedangkan tumor dengan differensiasi buruk sebanyak 28 orang (34,6\%). Dan dari pemeriksaan histologisnya 11 sampel $(13,6 \%)$ terbukti bermetastasis ke kelenjar getah bening (KGB)

Dari gambaran terapi tambahan selain terapi utama histerektomi bisalpingooforektomi, terdapat terapi adjuvan lainnya seperti tindakan limfadenektomi dilakukan pada 40 orang $(49,4 \%)$, kemoterapi 51 orang $(63 \%)$ dan radioterapi baik sinar dalam (brakiterapi) dan sinar luar sebanyak 52 orang $(64,2 \%)$.

Tabel 2. Kualitas Hidup (Quality Of Life) Penderita Kanker Endometrium di RSUP Dr. Sardjito

\begin{tabular}{|c|c|c|c|}
\hline $\begin{array}{c}\text { Domain Kualitas } \\
\text { Hidup }\end{array}$ & Mean & $\begin{array}{l}\text { Standard } \\
\text { Deviation }\end{array}$ & Median \\
\hline \multicolumn{4}{|l|}{ General (umum) } \\
\hline \multicolumn{4}{|c|}{ Status Kesehatan Global } \\
\hline $\begin{array}{l}\text { Skala kualitas } \\
\text { hidup }\end{array}$ & 79,94 & 13,68 & 83,33 \\
\hline \multicolumn{4}{|l|}{ Status Fungsi } \\
\hline Skala fisik & 84,94 & 13,03 & 86,67 \\
\hline Skala peran & 88,89 & 19,18 & 100 \\
\hline Skala emosional & 93 & 10,16 & 100 \\
\hline Skala kognitif & 93,21 & 13,12 & 100 \\
\hline Skala sosial & 91,56 & 14,22 & 100 \\
\hline \multicolumn{4}{|l|}{ Status Gejala Umum } \\
\hline Kelelahan & 73,53 & 19,76 & 77,78 \\
\hline Mual dan muntah & 94,86 & 13,6 & 100 \\
\hline Nyeri & 83,74 & 20,07 & 83,33 \\
\hline Dispnea & 96,71 & 11,31 & 100 \\
\hline Insomnia & 87,24 & 24,48 & 100 \\
\hline $\begin{array}{l}\text { Kehilangan selera } \\
\text { makan }\end{array}$ & 87,65 & 26,06 & 100 \\
\hline
\end{tabular}

$\begin{array}{llll}\text { Konstipasi } & 91,36 & 18,84 & 100 \\ \text { Diare } & 95,06 & 17,57 & 100 \\ \text { Kesulitan } & 94,24 & 14,71 & 100 \\ \text { keuangan } & & & \end{array}$

\begin{tabular}{|c|c|c|c|}
\hline \multicolumn{4}{|c|}{ Khusus (pasca tindakan) } \\
\hline \multicolumn{4}{|c|}{ Status Fungsi Seksual } \\
\hline $\begin{array}{l}\text { Skala fungsi } \\
\text { seksual }\end{array}$ & 81,76 & 22,94 & 100 \\
\hline \multicolumn{4}{|l|}{ Status Gejala Khusus } \\
\hline Limfedema & 95,88 & 9,69 & 100 \\
\hline Masalah urologi & 89,61 & 11,38 & 91,67 \\
\hline $\begin{array}{l}\text { Masalah } \\
\text { gastrointestinal }\end{array}$ & 93,09 & 8,78 & 93,33 \\
\hline Poor body image & 89,09 & 14,71 & 100 \\
\hline Masalah vagina & 71,19 & 36,8 & 100 \\
\hline Nyeri pelvis & 82,3 & 23,03 & 100 \\
\hline Bengkak & 86,01 & 20,32 & 100 \\
\hline Nyeri otot & 83,95 & 26,41 & 100 \\
\hline Rambut rontok & 71,19 & 36,8 & 100 \\
\hline Perubahan rasa & 95,06 & 15,91 & 100 \\
\hline
\end{tabular}

Pada tabel 2 menunjukkan rata-rata kualitas hidup pada domain status kesehatan global pasien kanker endometrium yang telah melakukan histerektomi total dan bisalpingooforektomi di RSUP Dr. Sardjito sebesar $79,94 \%$ dengan rentang 33,3\%-100,0\%. Dari data ini disimpulkan kualitas hidup secara status kesehatan global adalah baik. Demikian juga analisis kualitas hidup pada status lainnya baik status fungsi (fisik, peran, emosional, kognitif dan sosial), status gejala umum (kelelahan, mual dan muntah, nyeri, dispnea, insomnia, kehilangan selera makan, konstipasi, diare dan kesulitan keuangan), status fungsi seksual dan status gejala khusus (limfedema, masalah urogenital, masalah gastrointestinal, poor body image, masalah vagina, nyeri pelvis, bengkak kedua kaki, nyeri otot, rambut rontok dan perubahan rasa) memilki skor rata-rata $>70$ sehingga disimpulkan juga memilki status yang baik.

Untuk analisis hubungan variabel tergantung dengan variabel bebas atau juga variabel perancu digunakan uji Chi-square jika memenuhi syaratnya, jika tidak maka menggunakan uji Fisher yang disajikan pada tabel 3 . 
Tabel 3. Hubungan Variabel Bebas dan Luar dengan Variabel Tergantung

\begin{tabular}{|c|c|c|c|c|c|}
\hline \multirow{3}{*}{$\begin{array}{l}\text { Variabel bebas dan } \\
\text { perancu (Faktor } \\
\text { klinikohistopatologi) }\end{array}$} & \multicolumn{5}{|c|}{ Variabel Tergantung (Kualitas Hidup) } \\
\hline & Baik & Buruk & \multirow{2}{*}{$\mathbf{P}$} & \multirow{2}{*}{ PR } & \multirow{2}{*}{$\begin{array}{c}\mathrm{Cl} \\
95 \%\end{array}$} \\
\hline & $\mathbf{N}$ & $\mathbf{N}$ & & & \\
\hline \multicolumn{6}{|l|}{ Jenis histopatologi } \\
\hline Endometrioid & 60 & 17 & 0,045 & 3,12 & $1,03-7,08$ \\
\hline Non endometrioid & 1 & 3 & & & \\
\hline \multicolumn{6}{|l|}{ Differensiasi tumor } \\
\hline Baik & 45 & 8 & 0,006 & 1,49 & $1,06-2,09$ \\
\hline Buruk & 16 & 12 & & & \\
\hline \multicolumn{6}{|l|}{ Stadium kanker } \\
\hline Dini (I-II) & 55 & 12 & 0,004 & 1,92 & $1,04-3,54$ \\
\hline Lanjut (III-IV) & 6 & 8 & & & \\
\hline \multicolumn{6}{|l|}{ Keterlibatan KGB } \\
\hline Tidak & 52 & 18 & 0,723 & 0,91 & $0,66-1,24$ \\
\hline Iya & 9 & 2 & & & \\
\hline \multicolumn{6}{|l|}{ Usia } \\
\hline$<55$ tahun & 27 & 9 & 0,954 & 0,99 & $0,77-1,28$ \\
\hline$>=55$ tahun & 34 & 11 & & & \\
\hline \multicolumn{6}{|l|}{ Paritas } \\
\hline Nulipara & 18 & 5 & 0,698 & 1,26 & $0,39-3,97$ \\
\hline Multipara & 43 & 15 & & & \\
\hline \multicolumn{6}{|l|}{ Indeks Massa Tubuh (IMT) } \\
\hline Obesitas & 13 & 4 & 1 & 1,02 & $0,76-1,38$ \\
\hline Non obesitas & 48 & 16 & & & \\
\hline
\end{tabular}

Pada tabel 3 disimpulkan bahwa jenis histopatologi, differensiasi tumor dan stadium memiliki nilai yang signifikan terhadap kualitas hidup. Untuk jenis histopatologi endometrioid memiliki PR 3,12 dibandingkan non endometrioid dengan nilai $\mathrm{p}=0,045 \quad$ (Cl $95 \%$ 1,03-17,08). Sedangkan untuk differensiasi tumor untuk differensiasi baik memiliki PR 1,49 dibandingkan dengan differensiasi buruk dengan nilai $p=0,006(\mathrm{Cl}$ $95 \%$ 1,06-2,09). Begitu juga dengan stadium kanker, dimana stadium dini memiliki PR 1,92 dengan nilai $p=0,004$ (CI 95\% 1,04-3,54).

Dari analisis bivariat secara metode chi square didapatkan bahwa differensiasi tumor dan stadium memiliki hubungan yang signifikan dengan kualitas hidup, kemudian diolah kembali secara multivariat seperti yang disajikan pada tabel 4 .
Tabel 4. Hubungan Multivariat antara Variabel Bebas dan Tergantung

\begin{tabular}{|c|c|c|c|}
\hline Variabel Bebas & $\mathbf{P}$ & OR & Cl 95\% \\
\hline \multicolumn{4}{|l|}{ Stadium Kanker } \\
\hline Dini (I-II) & \multirow{2}{*}{0,024} & \multirow{2}{*}{4,57} & \multirow{2}{*}{$1,22-17,12$} \\
\hline Lanjut (III-IV) & & & \\
\hline \multicolumn{4}{|l|}{ Differensiasi tumor } \\
\hline Baik & \multirow{2}{*}{0,029} & \multirow{2}{*}{3,55} & \multirow{2}{*}{$1,14-11,04$} \\
\hline Buruk & & & \\
\hline \multicolumn{4}{|l|}{ Jenis Histopatologi } \\
\hline $\begin{array}{l}\text { Endometrioid } \\
\text { Non endometrioid }\end{array}$ & 0,251 & 2,57 & $0,41-31,43$ \\
\hline
\end{tabular}

Dari tabel 4. didapatkan nilai OR pada variabel differensiasi tumor adalah 3,55 (dengan nilai $p=0,029$ (CI95\% 1,14-11,04)) yang artinya bahwa kualitas hidup penderita kanker endometrium dengan differensiasi 
baik memiliki kualitas hidup 3,55 kali lebih baik dibandingkan dengan penderita dengan differensiasi buruk. Begitu juga jika melihat nilai OR pada variabel stadium kanker adalah 4,57 (dengan nilai $p=0,024$ (Cl $95 \%$ 1,22-17,12) yang artinya bahwa kualitas hidup penderita kanker endometrium dengan stadium kanker dini memiliki kualitas hidup 4,57 kali lebih baik dibandingkan dengan penderita dengan stadium kanker lanjut. Sedangkan untuk jenis histopatologi secara statistik tidak terbukti memiliki hubungan yang signifikan dengan kualitas hidup, namun tidak jika dilihat secara klinis dimana OR 2,57 (dengan nilai $p=0,251$ (Cl 95\% 0,41-31,43)), artinya secara klinis jenis histopatologi endometrioid memiliki kualitas hidup lebih baik 2,57 kali dibandingkan dengan jenis non endometrioid.

\section{KETERBATASAN PENELITIAN}

Penelitian retrospektif ini tentu memiliki beberapa kelemahan, adapun diantaranya:

- Penelitian ini juga tidak mengkaji hubungan pengaruh terapi adjuvant lainnya seperti radiasi dan kemoterapi dengan kualitas hidup pasien. Terapi tambahan lainnya diluar pasca operasi dan waktu saat pengambilan data juga dianggap mempengaruhi kualitas hidup pasien kanker endometrium pasca operasi..$^{27,28}$

- Penelitian ini juga tidak mengkaji hubungan variabel luar lainnya seperti genetik, riwayat keluarga, status menopause, riwayat $\mathrm{KB}$, dan hubungan dengan penyakit lainnya seperti: diabetes tipe 2, hipertensi, polycistic ovary syndrome (PCOS), kanker payudara, kanker ovarium, dan hiperplasia endometrium dengan kanker endometrium. ${ }^{29}$

- Pada kasus pembedahan kanker endometrium di RSUP Dr. Sardjito tidak semua nya dilakukan tindakan limfadenektomi. Hal ini mungkin disebabkan diagnosis stadium kanker, pemahaman terhadap protokol maupun guideline manajemen baru, dan kondisi pasien..$^{30,31,32}$

\section{KESIMPULAN}

Pada penelitian ini disimpulkan bahwa kualitas hidup penderita kanker endometrium yang telah dilakukan histerektomi total dan bisalpingooforektomi di RSUP
Dr. Sardjito baik, sehingga tindakan dan pengobatan pada kanker endometrium sudah tepat. Secara statistik, penelitian ini tidak dapat membuktikan hipotesis berikut ini, dimana:

1. Jenis histopatologi tidak terbukti memiliki hubungan dengan kualitas hidup penderita kanker endometrium secara statistik, namun memiliki hubungan signifikan secara klinis (OR 2,57, $p=0,251$ (Cl 95\% 0,41-31,43).

2. Keterlibatan kelenjar getah bening pelvik dan paraaorta tidak terbukti memiliki hubungan dengan kualitas hidup penderita kanker endometrium (PR 0,91, $p=0,723 f(C l 95 \%$ 0,661,24).

3. Usia, status paritas, dan indeks massa tubuh tidak terbukti memiliki hubungan dengan kualitas hidup penderita kanker endometrium.

Akan tetapi penelitian ini dapat membuktikan hipotesis, bahwa:

1. Pasien kanker endometrium stadium awal akan memiliki kualitas hidup yang lebih baik dibandingkan dengan stadium lanjut (OR 4,57, $\mathrm{p}=0,024(\mathrm{Cl} 95 \%$ 1,2-17,12)).

2. Pasien kanker endometrium dengan derajat 1 dan 2 (differensiasi baik) akan memiliki kualitas hidup yang lebih baik dibandingkan dengan derajat 3 (differensiasi buruk) (OR 3,55, p=0,029 (Cl 95\% 1,14-11,04)).

\section{SARAN}

Kualitas hidup penderita kanker endometrium pasca operasi akan memberikan harapan hidup yang lebih panjang. Sehingga penelitian yang berlanjut sangat diharapkan untuk lebih memberikan manfaat terhadap penderita terutama memperbaiki kualitas hidup, prognosis penyakit, dan ketahanan hidup melawan kanker endometrium. ${ }^{13}$

\section{DAFTAR PUSTAKA}

1. Colombo, N., Creutzberg, C., Amant, F., Bosse, T., González-Martín, A., Ledermann, J., Sessa, C. (2016). ESMO-ESGO-ESTRO Consensus Conference on Endometrial Cancer: diagnosis, treatment and follow-up. Annals of Oncology, 27(1), 16-41. https://doi.org/10.1093/annonc/mdv484. 
2. Evans T, Sany O, Pearmain P, Ganesan R, Blann A, Sundar S. Differential trends in the rising incidence of endometrial cancer by type: data from a UK population-based registry from 1994 to 2006. Br J Cancer. 2011; 104(9): p.1505-1510.

3. Helder-Woolderlink J, De Bock G, Sijmons Rea. The additional value of endometrial sampling in the early detection of endometrial cancer in women with Lynch syndrome. Gynecol Oncol 2013; 131(2): p.304-308.

4. Hoskins WJ, Perez CA, Young RC, Barakat RR, Markman M, Randall ME. Principles and practice of gynecologic oncology, 4th ed. Philadelphia: Lippincott Williams \& Wilkins; 2005. p. 823-63.

5. Badan Registrasi Kanker IAPI. Data Histopatologi Kanker di Indonesia. Jakarta: Dirjen. Pelayanan Medik Departemen Kesesehatan Rl; 2013.

6. Boente MP, Yordan ELJ, Mclntosh DG, Grendys ECJ, Orandi YA, Davies S. Prognostic factors and long-term survival in endometrial adenocarcinoma with cervical involvement. Gynecol Oncol 1993; 51(3): p.316-322.

7. Brinton LA, Felix AS, McMeekin DS, Creasman WT, Sherman ME, Mutch D. Etiologic heterogeneity in endometrial cancer: evidence from a Gynecologic Oncology Group trial. Gynecol Oncol. 2013; 129: p.277-84.

8. Eto T., Saito T., Kasamatsu T., Nakanishi T., Yokota H., Satoh T. Clinicopathological prognostic factors and the role of cytoreduction in surgical stage IVb endometrial cancer: a retrospective multi-institutional analysis of 248 patients in Japan. Gynecol Oncol. 2012; 127(2): p.338-344.

9. Rosenberg P, Risberg B, Askmalm L, Simonsen E. The prognosis in early endometrial carcinoma. The importance of uterine papillary serous carcinoma (UPSC), age, FIGO grade and nuclear grade. Acta Obstet Gynecol Scand. 1989; 68(2): p.157-163.

10. Varughese J, Richman S. Women's Health in the Developing World. Cancer Care Inequity for Women in Resource-Poor Countries. 2010; 3(1):122-32.

11. Greimel E, Nordin AJ. Application of quality of life measurements in clinical trials and in clinical practice for gynecologic cancer patients. Expert Rev Pharmacoecon Outcomes Res. 2010.
12. Kornblith $A B$, Huang $H Q$, Walker JL, Spirtos NM, Rotmensch J, Cella D. Quality of life of patients with endometrial cancer undergoing laparoscopic international federation of gynecology and obstetrics staging compared with laparotomy: a Gynecologic Oncology Group. J Clin Oncol. 2010.

13. World Cancer Research Fund/ American Institute for Cancer Research. Food, Nutrition, Physical Activity, and the Prevention of Cancer: Endometrial cancer 2013 report. 2013.

14. National Cancer Institute. Endometrial Cancer. National Institute of Health; 2010.

15. Hoffman, BL; Schorge, JO; Schaffer, Jl; Halvorson, LM; Bradshaw, KD; Cunningham, FG eds. Endometrial Cancer. In: Williams Gynecology (2nd ed). McGraw-Hill. p; 2012. 819-34.

16. Ota $T$, Yoshida $M$, Kimura $M$, Kinoshita $K$. Clinicopathologic study of uterine endometrial carcinoma in young women aged 40 years and younger. Int J Gynecol Cancer. 2005; 15: p.657-662.

17. Pellerin GP, Finan MA. Endometrial cancer in women 45 years of age or younger: A clinicopathological analysis. Am J Obstet Gynecol 2005; p.1640-4.

18. Yasumizu T, Ogawa K, Kato J. Comparison of the clinicopathological characteristics of premenopausalandpostmenopausalendometrial carcinomas: analysis of endocrinologically evaluated cases. Jpn J Clin Oncol. 1996: p.152-6.

19. Angioli R., Plotti F., Cafa E.V., Dugo N., Capriglione S., Terranova C. "Quality of life in patients with endometrial cancer treated with or without systematic lymphadenectomy". Eur. J. Obstet. Gynecol. Reprod. Biol. 2013.

20. Cella DF. Quality of life outcomes: measurement and validation. Oncology (Williston Park). 1996.

21. Cocks K, King MT, Velikova G. Evidence-based guidelines for interpreting change scores for the European Organisation for the Research and Treatment of Cancer Quality of Life Questionnaire Core 30. Eur J Cancer. 2012; 48(11): p.1713-1721.

22. Dobrzycka B, Terlikowski R, Kulesza-bronczyk B, Niklinski J. Quality of life in long-term survivors of early stage endometrial cancer. 2017; 24(3): p. 513-6. 
23. Aaronson NK, Ahmedzai S, Bergman B. The European Organization for Research and Treatment of Cancer QLQ-C30: a quality-of-life instrument for use in international clinical trials in oncology. J Natl Cancer Inst. 1993.

24. Fayers PM. AN, Bjordal K., Groenvold M., Curran D., Bottomley A. EORTC QLQ-C30 Scoring Manual. 3rd ed. Brussels: European Organisation for Research and Treatment of Cancer. 2001.

25. Stukan M, Zalewski K, Mardas M. Independent psychometric validation of European Organization for Research and Treatment of Cancer Quality of Life QuestionnaireEndometrial Cancer Module (EORTC QLQ-EN24). Eur J Cancer Care. 2018; p.27.

26. lang Yuan, Uan, Heng WZ, Heng JC. Menstrual and reproductive factors and endometrial cancer risk: results from a population-based casecontrol study in urban shanghai. Int J Cancer. 2004: 613-9.

27. ASTEC/EN.5 Study Group. Adjuvant external beam radiotherapy in the treatment of endometrial cancer (MRC ASTEC and NCIC CTG EN.5 randomised trials): pooled trial results, systematic review, and meta-analysis. Lancet. 2009.

28. Benedetti-Panici P, Basile S, Maneschi F, Lissoni AA, Signorelli M, Scambia G. Systematic pelvic lymphadenectomy in early-stage endometrial carcinoma: randomised clinical trial. J Natl Cancer Inst. 2008; 100(23): p.1707-1716.
29. Thomas CC, Wingo PA, Dolan MS, Lee NC, Richardson LC. Endometrial cancer risk among younger, overweight women. Obstet Gynecol. 2009; p.114:22-7.

30. Lax SF, Kurman RJ, Pizer ES, Wu L, Ronnett BM. A binary architectural grading system for uterine endoemetrial endometrioid carcinoma has superior reproducibility compared with FIGO grading and identifies subsets of advancedstage tumors with favorable and unfavorable prognosis. Am J Surg Pathol 2000; 24: 1201-1208.

31. Wright JD, Fiorelli J, Kansler AL, Burke WM, Schiff $\mathrm{PB}$, Cohen $\mathrm{CJ}$. Optimizing the management of stage II endometrial cancer: the role of radical hysterectomy and radiation. Am J Obstet Gynecol. 2009: 200(4): p.419.e1-7.

32. National Institute for Health and Care Excellence. NICE guidelines (NG12) Suspected cancer: recognition and referral. June 2015. Available at: https://www.nice.org.uk/guidance/ng12.

33. Johnson N, Cornes P. Survival and recurrent disease after postoperative radiotherapy for early endometrial cancer: systematic review and meta-analysis. Br J Obstet Gynaecol 2007; 114: 1313-1320. 